Deniz Kamacı Şener

Özlem Taşkapılıoğlu

Nermin Kelebek Girgin

Bahattin Hakyemez

Mustafa Bakar

\section{Travmatik Karotis Arter Diseksiyonuna Bağlı Serebral İskemi: Olgu Sunumu}

\author{
Cerebral Ischemia Due to Traumatic Carotid Artery \\ Dissection: Case Report
}

Geliş Tarihi/Received: 13.08 .2012

Kabul Tarihi/Accepted: 12.09.2012

Türk Yoğun Bakım Derneği Dergisi, Galenos Yayınevi tarafından basılmıştır.

Journal of the Turkish Society of Intensive Care, published by Galenos Publishing.

ISNN: 1300-5804

Deniz Kamacı Şener (凶), Özlem Taşkapııı̆̆lu, Mustafa Bakar, Yakup Tomak

Uludağ Üniversitesi Tıp Fakültesi, Nöroloji Anabilim Dalı, Bursa, Türkiye

Nermin Kelebek Girgin

Uludağ Üniversitesi Tıp Fakültesi, Anesteziyoloji ve

Reanimasyon Anabilim Dalı, Bursa, Türkiye

Bahattin Hakyemez

Uludağ Üniversitesi Tıp Fakültesi, Radyoloji Anabilim

Dalı, Bursa, Türkiye

E-posta: drdenizkamaci@gmail.com
ÖZET Boyun bölgesine yönelik künt bir travma, karotis arter diseksiyonuna ve serebral iskemiye neden olabilir. Karotis arterinin künt travması sık görülen bir durum olmadığından olguların travma varlığı açısından sorgulanması ve tetkik edilmesi erken tanı ve tedavi şansını sağlayacaktır. Bu yazıda, travmatik karotis arter diseksiyonuna bağlı serebral enfarkt gelişen bir hasta sunulmuş, olgunun klinik özellikleri, uygulanan tanı ve tedavi yöntemlerinin seçimi literatür bilgisi ile birlikte tartışılmıştır.

Anahtar Kelimeler: Diseksiyon, iskemi, enfarkt, karotis arter, travma
SUMMARY Blunt injury to the neck region may lead to carotid artery dissection and cerebral ischemia. Blunt injury to carotid artery is not frequent but determination of the presence of trauma in the history of stroke patients will provide early diagnosis and treatment of them. In this article, a case with cerebral ischemia resulting from traumatic carotid artery dissection is presented and clinical findings, diagnostic procedures and choice of treatment are discussed in the light of the literature.

Key Words: Carotid artery, dissection, ischemia, infarction, trauma

\section{Giriş}

Diseksiyon, sıklıkla arterin intima tabakasının media tabakasından ayrımasını, daha nadir olarak da media tabakasının adventisya tabakasının ayrımasını tanımlamak üzere kullanılan bir terimdir. Diseksiyona sıklıkla arter duvarının içine olan kanama eşlik eder. Örneğin karotis artere yönelik bir travmaya bağlı olarak intima tabakasında yırtılma olur; kan, yalancı bir lümen oluşturarak arter boyunca ilerler (1-3).

Arter diseksiyonu travmaya bağlı olarak veya spontan oluşabilir. Karotis arter diseksiyonunun en sık sebebi boyun bölgesine alınan künt travmadır. Karotis arterinin künt travmasının görülme sıklığının, künt travma geçiren hastaların \%1'inden azında olduğu bildirilmiștir. Az rastlanmasına rağmen bu durumun mortalitesinin \%5-40 arasında olması, erken tanı ve tedaviyi önemli hale getirmektedir (4). Bu yazıda, nadir görülen bir tablo olan künt karotis arter travmasına bağlı karotis arter diseksiyonu sonucu serebral enfarkt gelişen bir hastanın klinik özellikleri, uygulanan tanı ve tedavi yöntemleri literatür bilgisi ile birlikte tartışılmıştır.

\section{Olgu}

40 yaşında erkek hasta, araç içi trafik kazası sonrası acil servise getirildi. Illk değerlendirildiğinde genel durumu orta, vital 
bulguları stabil, Glasgow koma skalası 15, APACHE II skoru 9 ve nörolojik defisiti yoktu. Fizik muayenesinde sağ göz çevresinde ve pelviste yaygın abrasyon ve ekimoz saptandı. Sternum üzerine dokunmakla hassas, batın derin palpasyonla ağrılı, sol omuz palpasyonla ağrılı ve krepitasyon mevcuttu. Çoklu travma olgusu, PA akciğer grafisi, toraks bilgisayarlı tomografisi (BT), batın Doppler ultrasonografi, batın BT ve kraniyal BT ile değerlendirildi. Bu tetkikler sonucunda sol plevral aralıkta pnömotoraks, aynı lokalizasyonda cilt altında amfizem, sol klavikulada ve sağ frontal bölgede travmaya sekonder lineer nondeplese fraktür saptandı. Sol klavikuladaki kıı̆ga yönelik omuz bandajı uygulanan hastanın acil servisteki takibinin 4. saatinde hastada aniden sol nazolabial oluk silikliği, sol kol ve bacağında güçsüzlük gelişti. Nörolojik muayenesinde sol nazolabial olukta silinme, sol kolda pleji, sol bacakta \%60 kas gücü, solda Babinski belirtisi ve soldaki odaklarda derin tendon reflekslerinde artış saptandı. Yüzü de içine alan 1. motor nöron tipi hemipareziyi açılamak üzere çekilen kraniyal difüzyon manyetik rezonans (MR) görüntülemede sağ orta serebral arter sulama alanına uyan hiperintens görünüm mevcuttu. T2 ağırlıkı imajlarda sağ internal karotis arterin izlenmediği saptandı (Resim 1). Çoklu travma varlığı nedeni ile Reanimasyon Yoğun Bakım Ünitesi'ne yatırılan hastanın kraniyal MR'daki görünümünün karotis arter diseksiyonuna bağı akut enfarkt ile uyumlu olduğu düşünülerek tedavisi düşük molekül ağırlıklı heparin $(0,8 \mathrm{ml} / \mathrm{gün})$ olarak düzenlendi. Hasta sol kol ve bacağında \%60 kas gücü ile asetilsalisilik asit 300 mg/gün tedavisi ile takibe alındı.

\section{Tartıșma}

Travmatik karotis arter diseksiyonun sebebi boyun bölgesine alınan künt veya penetran travmalardır (1). Karotis arter diseksiyonu spontan ya da travmaya bağlı gelişebilir. Neden olan travmalarııın başında motorlu araç kazaları gelmektedir. Karotis arterin C1-2 vertebraları hizasında olan kısmı travmaya çok duyarlıdır. Servikal bölgede vertebraların hiperekstansiyon travması, başın ani dönüş ve lateral fleksiyona gelişi, internal karotis arterin gerilmesine ve damarın intima tabakasında hasara

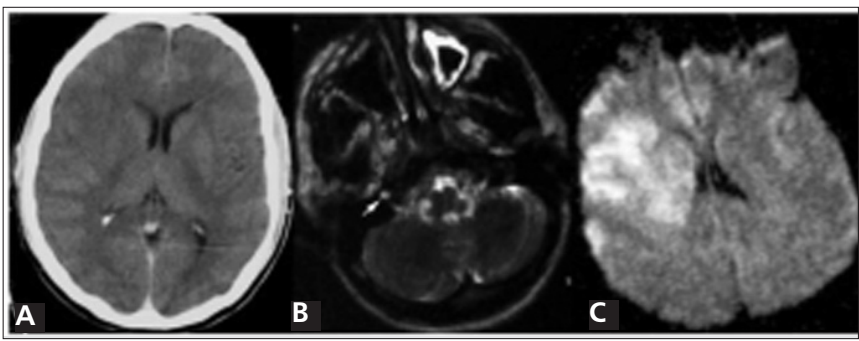

Resim 1. Kraniyal BT görüntüde (A) beyin parankimi normal; aksiyal planda T2-ağırlıklı FSE (B) MR görüntüde, sağ internal karotis arter hiperintens (ok); difüzyon MR görüntüde (C) sağ orta serebral arter alanına uyan akut enfarkt lezyonu görülmektedir neden olmaktadır (2,3). Motorlu araç kazası esnasında emniyet kemerinin boyuna aniden basısı sonrasında da diseksiyon tablosu görülebilir (5). Trafik kazası sırasında emniyet kemeri bağlı olan olgunun boynunun hiperekstansiyonu ve lateral fleksiyonu sonucu internal karotis arterin gerilmesinin diseksiyona neden olabileceği düșünülmüștür $(4,5)$.

Travmaya bağlı arter diseksiyonunda temel mekanizma, arterin intima tabakasında yırtılma ve o bölgedeki kanın arter boyunca ilerleyerek subintimal ya da subadventisyal tabakalar içinde yalancı bir lümen oluşturmasıdır. Karotis arter diseksiyonunda damar duvarının elastikiyeti, ateroskleroz, intimal kalınlaşma gibi risk faktörleri ve displazisi patolojiden sorumlu tutulmuştur (6). Fibromusküler displazi, Ehler-Danlos sendromu tip 4 ve Marfan sendromu gibi elastik doku hastaliklarında arter duvarında olan bozukluklar predispozan faktörler arasındadır $(7,8)$. Bu hastada araç içi trafik kazası dışında bilinen başka bir predispozan faktör yoktu.

Arter diseksiyonda arterin intima tabakasından media tabakasına kanama olur, hematom intima tabakasından internal elastil membranı ayırarak damar lümenin daralmasına neden olur. Internal karotis arterdeki daralma, tıkanma, intrakraniyal damarlara kan geçisinin önlenmesi ya da emboli sonucu serebral iskemi gelişir (9). Disseke arter lümeninden intrakraniyal damarlara doğru olan emboli sonucu serebral iskemi olur ve emboli genellikle orta serebral arterde görülür (4).

Diseksiyon sonrası geçici iskemik atak, serebral iskemi sonucu unilateral motor ve duyu kayıpları, afazi, görme kaybı, başağrısı, internal karotis arter çevresindeki pleksusun tutulumuna bağlı olarak Horner sendromu gelişebileceği gibi asemptomatik olgular da bildirilmiştir $(10,11)$. Mortalite ve morbiditesi yüksek olan ölümle sonuçlanabilen bir tablodur (11). Diseksiyon olan bir hastada başlangıçta semptom bulunmayabilir. Başlangıçta asemptomatik kalan intima hasarları kronikleşerek yıllar sonra tromboembolik mekanizmayla semptom verebilir (2). Sunulan olgu başlangıçta nörolojik açıdan asemptomatik iken travma sonrası 4. saatte serebral iskemi kliniği ortaya çıkmıştır.

Diseksiyon görülen olguları yaklaşık \%50'sinde hastanın fizik muayenesinde inspeksiyonda boyun bölgesinde herhangi bir patolojiye rastlanmaz (3). Olgumuzda inspeksiyonda boyun bölgesinde travmaya ait herhangi bir değişiklik izlenmezken sternum üzeri basmakla hassas idi. Travmaya maruz kalmış bir hastada gelişen serebral iskemik olay sonrası çekilen kraniyal BT'de semptomları açıklayacak bir patolojiye rastlanmaz ise MR ve MR anjiografi yapılmalıdır. MR anjiografi diseksiyonlu hastada yapılabilecek en uygun girişimsel olmayan görüntüleme yöntemidir (12). Tanı koymak için kullanılabilecek diğer radyolojik yöntemler; Doppler USG, BT anjiografidir. Çoklu travması olan ve yoğun bakım ünitesinde izlenen bu olguda tanı, öyküdeki travma varlığında ve difüzyon MR incelemesinde T2 ağırlıkı imajlarda sağ internal karotid arterin kodlanmadığı görünerek konmuştur. Mevcut durumun kardiyak bir emboliye sekonder gelişme olasılığı teorik olarak vardır ama hastanın araç içi travma hastası 
olması düşünüldüğünde diseksiyon öncelikli tanıdır. Ayrıca hastanın genç inme yönünden diğer tetkiklerinde kardiyak ve hematolojik bir neden saptanmamıştır.

Travmatik karotis arter diseksiyonunun medikal tedavisinde antikoagülan tedavi birinci seçenektir. Antikoagülasyonun amacı, hasarlı diseksiyon bölgesinden köken alabilecek embolilerin ve damarın kendisinde olabilecek tıkanıklıkların önlenmesidir. Tedaviye genellikle heparin ile başlanıp idame tedavisinde varfarin kullanıı. Varfarin ile 6 ay takip edilen hastalarda klinik iyileşme saptanmıştır. Antikoagülan tedavi almasına rağmen nörolojik kötüleşmesi olan, kanama riski nedeni ile antikoagülan alamayan, psödoanevrizması olan hastalarda cerrahi tedavi yapılabilir $(13,14)$. Heparin çoklu travmalı bir hastada kanama riskini arttırabilir. Bu nedenle olgumuzda tedavi seçeneği olarak heparin yerine düşük molekül ağırlıklı heparin seçildi. Altta yatan arter hastalığı ya da rezidü anevrizma varlığında kanama riskini azaltmak için antiagregan tedavinin de verilebildiği bilinmektedir. Hastamı daha sonra asetilsalisilik asit 300 mg/gün tedavisi ile takibe alınmıştır.

Özellikle motorlu taşıt kazası sonucu travmaya maruz kalıp acil servise getirilen hastalarda asemptomatik bile olsalar arter diseksiyonu mutlaka akla getirilmeli; en kısa sürede hastanın tanısı konarak tedaviye başlanmasının mortalitesi yüksek bu hastalıkta önemi akıldan çıkarılmamalıdır.

\section{Kaynaklar}

1. Guyot LL, Kazmierczak CD, Diaz FG. Vascular injury in neurotrauma. Neurol Res 2001;23:291-6.

2. Okada Y, Shima T, Nishida M, Yamane K, Kagawa R. Traumatic dissection of the common carotid artery after blunt injury to the neck. Surg Neurol 1999;51:513-9 discussion 519-20.

3. Kindelberger D, Gilmore K, Catanese CA, Armbrustmacher WW. Hyperextension and rotation of head causing internal carotid artery laceration with basilar subarachnoid hematoma. J Forensic Sci 2003:48:1366-8.

4. Kraus RR, Bergstein JM, DeBord JR. Diagnosis, treatment, and outcome of blunt carotid arterial injuries. Am J Surg 1999;178:190-3.

5. Doi A, Deguchi J, Yamada M, Shimano H, Nagao K, Arai M, et al. Traumatic internal carotid artery dissection due to compression by a helmet strap. No Shinkei Geka 2004;32:1279-82.
6. Calvet D, Boutouyrie P, Touze E, Laloux B, Mas JL, Laurent $\mathrm{S}$. Increased stiffness of the carotid wall material in patients with spontaneous cervical artery dissection. Stroke 2004;35:2078-82.

7. Mokri B, Sundt TM Jr, Houser OW, Piepgras DG. Spontaneous dissection of the cervical internal carotid artery. Ann Neurol 1986;19:126-38.

8. Duncan MA, Dowd N, Rawluk D, Cunningham AJ. Traumatic bilateral internal carotid artery dissection following airbag deployment in a patient with fibromuscular dysplasia. Br J Anaesth 2000;85:476-8.

9. Burke JP, Marion DW. Cerebral revascularization in trauma and carotid occlusion. Neurosurg Clin N Am 2001;12:595-611.

10. Ringer AJ, Fessler RD, Qureshi Al, Guterman LR, Hopkins LN. Horner's syndrome after carotid artery stenting: case report. Surg Neurol 2000;54:439-43.
11. Rajz G, Simon D, Bakon M, Goren O, Zauberman J, Zibly Z, et al. Traumatic carotid artery dissection. Isr Med Assoc J 2009;11:507-8.

12. Gelal FM, Kitis $\mathrm{O}$, Calli $C$, Yunten $N$, Vidinli $\mathrm{BD}$, Uygur M. Craniocervical artery dissection: diagnosis and follow-up with MR imaging and MR angiography. Med Sci Monit 2004;10:109-16.

13. Pagnotta P, Briguori C, Saluzzo CM, Presbitero P. Endovascular treatment of traumatic bilateral internal carotid artery dissection. J Invasive Cardiol 2009;21:E6-8.

14. Kilinçer C, Tiryaki M, Celik Y, Turgut N, Balci $\mathrm{K}$, Utku $\mathrm{U}$, et al. Cerebral infarction due to traumatic carotid artery dissection: case report and review of current management. Ulus Travma Acil Cerrahi Derg 2008;14:333-7. 